\title{
AdsorÇÃo e DessorÇÃo de Trifloxysulfuron-SOdium E AMETRYN EM SOLOS BRASILEIROS ${ }^{1}$
}

\author{
Adsorption-Desorption of Trifloxysulfuron-Sodium and Ametryn in Brazilian Soils
}

VIVIAN, R. ${ }^{2}$, GUIMARÃES, A.A. ${ }^{3}$, QUEIROZ, M.E.L.R. ${ }^{4}$, SILVA, A.A. ${ }^{5}$, REIS, M.R. ${ }^{6}$ e SANTOS, J.B. ${ }^{7}$

\begin{abstract}
RESUMO - O estudo objetivou avaliar os coeficientes adsortivos e dessortivos de ametryn e trifloxysulfuron-sodium em seis solos brasileiros, com intuito de prever o comportamento e o potencial de movimentação desses herbicidas nos solos. Utilizou-se o método Batch slurry, conduzido em condições controladas de laboratório. Para isso, 10,0 mL das soluções em $\mathrm{CaCl}_{2}$ $0,01 \mathrm{~mol} \mathrm{~L}^{-1}$, contendo $0,5,10,25,50$ e $100 \mu \mathrm{g} \mathrm{mL} \mathrm{m}^{-1}$ de ametryn e 0;0,25;0,5; 1,0;2,0; e 4,0 $\mu \mathrm{g} \mathrm{mL}^{-1}$ de trifloxysulfuron-sodium, foram adicionadas em frascos com 2,0 g de solo, permanecendo sob agitação orbital até atingir o tempo de equilíbrio. Após centrifugação e filtração, a concentração do sobrenadante foi determinada por cromatografia líquida de alta eficiência (CLAE), com detector UV a $245 \mathrm{~nm}$. A dessorção foi avaliada para a maior dosagem utilizada de cada composto. O solo Latossolo Vermelho distroférrico - LVdf (Sete Lagoas) apresentou o maior coeficiente de adsorção (Kf) para ambos os herbicidas, sendo o mesmo atribuído ao seu elevado teor de matéria orgânica (MO). Verificou-se correlação positiva do Kf de ametryn com MO $(0,81)$, percentual de argila (ARG) $(0,80)$ e capacidade de troca catiônica (CTC) $(0,75)$ dos solos, sendo a MO identificada como o principal contribuinte na sua adsorção. Entretanto, o Kf de trifloxysulfuron-sodium apresentou apenas pequena correlação com ARG $(0,48)$ e MO $(0,28)$, sendo sua adsorção dependente, possivelmente, do teor de óxidos de Fe e Al presentes no solo. Baixos índices $\mathrm{H}$ de histerese foram verificados no ametryn em relação a trifloxysulfuron-sodium, representando maior potencial de dessorção e, conseqüentemente, risco de lixiviação desse herbicida no perfil dos solos estudados.
\end{abstract}

Palavras-chave: herbicidas, adsorção, isotermas de Freundlich, lixiviação.

\begin{abstract}
The aim of this work was to evaluate the adsorption and desorption coefficients of ametryn and trifloxysulfuron-sodium in six Brazilian soils to predict the potential of behavior and movement of these herbicides on soils. The "Batch slurry" method was used under controlled laboratory conditions. Thus, $10.0 \mathrm{~mL}$ of solutions in $\mathrm{CaCl}_{2} 0.01 \mathrm{~mol} \mathrm{L^{-1 }}$, containing 0, 5, 10, 25, 50 and $100 \mu \mathrm{g} \mathrm{mL} \mathrm{L}^{-1}$ of ametryn and $0,0.25,0.5,1.0,2.0$ and $4.0 \mu \mathrm{g} \mathrm{mL^{-1 }}$ of trifloxysulfuron-sodium, were added to flasks containing $2.0 \mathrm{~g}$ soil, under orbital agitation until reaching balance time. After centrifugation and filtration, supernatant concentration was quantified by High Performance Liquid Chromatography (HPLC), with $245 \mathrm{~nm} U$ V detector. Desorption was evaluated considering the highest dosage of each compound. The Rhodic Hapludox soil (Sete Lagoas) presented the highest coefficient of adsorption (Kf) for both herbicides, due to its high amount of organic matter (OM). Positive correlation of ametryn Kf was verified with $O M(0.81)$, clay percentage $(A R G)(0.80)$ and cation exchange capacity (CEC) (0.75) of the soils, while OM was the main contributor to its adsorption. However, Kf of trifloxysulfuron-sodium presented only a small correlation with ARG (0.48) and OM (0.28), as its adsorption was possibly dependent on oxides of Fe and Al. Low hysteresis index H was verified for ametryn in relation to trifloxysulfuron-sodium, representing higher desorption potential and, consequently, leaching risk for that herbicide on the profile of the soils analyzed.
\end{abstract}

Keywords: herbicides, adsorption, Freundlich isotherms, leaching.

Recebido para publicação em 11.4.2006 e na forma revisada em 27.2.2007.

Bolsista CAPES - Estudante de Doutorado do Dep. de Fitotecnia, Escola Superior de Agricultura "Luiz de Queiroz" - ESALQ/ USP, Av. Pádua Dias, 11, 13418-900 Piracicaba-SP, <agrovivian@yahoo.com.br>. ${ }^{3}$ Acadêmica do curso de Agronomia da Universidade Federal de Viçosa - UFV, 36570-000 Viçosa-MG; ${ }^{4}$ Professora do Dep. de Química - DEQ/UFV; ${ }^{5}$ Professor Associado - DFT/UFV; ${ }^{6}$ Estudante de Mestrado do Dep. de Fitotecnia - DFT/UFV; ${ }^{7}$ Prof. de Agronomia - FAAG/UNIVALE. 


\section{INTRODUÇÃO}

Os processos de adsorção e dessorção são determinantes no destino e movimento de herbicidas no solo (Ahmad et al., 2001; Selim \& Zhu, 2005); a compreensão deles permite avaliar a eficiência e o potencial de contaminação do ambiente por esses compostos (Lavorenti, 1999; Hinz, 2001). Entretanto, a dinâmica desses processos depende, além das propriedades dos solos, das características dos compostos estudados, incluindo estrutura, tamanho e configuração molecular, polaridade, distribuição de cargas e natureza ácido-base dos herbicidas.

Geralmente, em solos que apresentam altos teores de argila, de matéria orgânica ou ambos, verifica-se maior adsorção e persistência de herbicidas, seguido por baixos índices de dessorção, lixiviação e degradação destes (Li et al., 2003; Hager \& Nordby, 2004; Si et al., 2005). Entretanto, estudos mais amplos têm demonstrado que os mecanismos que governam os processos de retenção de herbicidas ocorrem de forma distinta para cada solo e seu ecossistema e que a heterogeneidade desse meio dificulta a previsão de comportamento desses compostos (Pusino, 1993; Pusino et al., 2004). Assim, enquanto muitos estudos avaliam, separadamente, frações orgânicas e minerais dos solos, com objetivo de esclarecer os mecanismos envolvidos na retenção de herbicidas, poucos esforços visam prever o seu comportamento em relação ao solo como um todo, principalmente em solos brasileiros intemperizados (Racke, 1996; Oliveira et al., 2005; Laabs et al., 2002). Em trabalho realizado por Procópio et al. (2001), verificou-se que a interação de argilominerais e compostos orgânicos do solo, com a formação de complexos adsortivos, atuou de forma diferenciada em relação às frações orgânicas ou minerais, enfatizando a necessidade de avaliar os fenômenos de adsorção de herbicidas e os seus riscos de lixiviação em diferentes solos.

Sabe-se também que minerais de argila expansiveis, como montmorilonita e vermiculita, apresentam maior capacidade de adsorção de herbicidas devido às cargas geradas a partir das substituições iônicas isomórficas nas estruturas desses minerais (Fontes et al., 2001). Já minerais como a caulinita e os óxidos de ferro e alumínio (goethita, hematita e gibbsita), predominantes nas regiões brasileiras de clima tropical, possuem cargas dependentes de $\mathrm{pH}$, devido à protonação ou desprotonação dos grupamentos hidroxila, podendo reter herbicidas de caráter ácido ou básico na sua forma dissociada (Goetz et al., 1989; Fontes et al., 2001).

Algumas classes de herbicidas têm apresentado maior risco e persistência no ambiente, as quais incluem as triazinas, feniluréias, sulfoniluréias e dinitroanilinas (Hager \& Nordby, 2004). Entre elas, os herbicidas ametryn e trifloxysulfuron-sodium, pertencentes aos grupos das s-triazinas e sulfoniluréias, respectivamente, embora muito utilizados em lavouras de cana-de-açúcar, ainda não possuem estudos de adsorção e dessorção em solos brasileiros. Além disso, o índice adsortivo obtido por Chefetz et al. (2004) para ametryn foi semelhante ao verificado para atrazine, o qual é reconhecido como um dos principais contaminantes de águas superficiais e subterrâneas em áreas agrícolas (Gooddy et al., 2005; Selim \& Zhu, 2005).

Considerando o exposto, objetivou-se com este trabalho investigar a capacidade de adsorção e dessorção dos herbicidas ametryn e trifloxysulfuron-sodium em seis solos característicos brasileiros, servindo como indicativo do potencial de contaminação do ambiente por esses compostos.

\section{MATERIAL E MÉTODOS}

\section{Caracterização dos solos e herbicidas avaliados}

Os seis solos selecionados, LVdf-(SL), PVAe-(PN), LVd-(SSP), LVe-(CE), LVAd-(JP) e RQ-(TM) (Tabela 1), foram coletados em áreas isentas da aplicação de herbicidas, na profundidade de 0 a $20 \mathrm{~cm}$, peneirados em malha de $2 \mathrm{~mm}$ e, posteriormente, secados ao ar e à sombra, para o seu armazenamento. Eles foram caracterizados fisica e quimicamente (Tabela 1), além da identificação dos minerais presentes na fração argila, a qual foi previamente tratada para destruição da fração orgânica e remoção de óxidos de ferro livre. Os herbicidas ametryn e trifloxysulfuron-sodium foram fornecidos pela Syngenta, apresentando, 
respectivamente, pureza de 98,3 e 95\%, solubilidade de $200 \mathrm{mg} \mathrm{L}^{-1}\left(22^{\circ} \mathrm{C}\right)$ e $352 \mathrm{mg} \mathrm{L}^{-1}$ $\left(25^{\circ} \mathrm{C}\right)$, pKa de 4,10 e 4,76 e log kow de 2,63 e 1,4 .

\section{Determinação do tempo de equilibrio de adsorção}

Avaliou-se, previamente, o tempo necessário para que se estabelecesse o equilibrio de adsorção entre os solos e os herbicidas testados. Para isso, utilizou-se o método de Batch slurry, baseado na OECD (1993), no qual soluções contendo $10,0 \mathrm{mg} \mathrm{L}^{-1}$ de ametryn e trifloxysulfuron-sodium (grau técnico) foram preparadas em solução de $\mathrm{CaCl}_{2}$ 0,01 mol L-1. Posteriormente, $10,0 \mathrm{~mL}$ da solução de $\mathrm{CaCl}_{2}$ 0,01 $\mathrm{mol} \mathrm{L}^{-1}$, juntamente com os herbicidas, foram adicionados a tubos de polipropileno contendo $2,0 \mathrm{~g}$ de cada solo. $\mathrm{O}$ pH da solução foi ajustado para 5,4 $\pm 0,1$, utilizando-se $\mathrm{HCl}$ ou $\mathrm{Ca}(\mathrm{OH})_{2}$. Cada frasco contendo a solução mais o substrato foi colocado sob agitação orbital, em diferentes intervalos de tempo: 8, $16,24,32$, 40 e 48 horas para trifloxysulfuronsodium e 4, 8, 12, 16, 20 e 24 horas para o herbicida ametryn. Após agitação, em sala com temperatura controlada por condicionador de ar a $24 \pm 2{ }^{\circ} \mathrm{C}$, as amostras foram centrifugadas a $1.600 \mathrm{xg}$, por sete minutos, em centrifuga digital Fanem_sem controlador de temperatura. O sobrenadante foi filtrado em filtro Millipore com membrana PTFE de 0,45 $\mu \mathrm{m}$, para análise cromatográfica. A quantificação foi realizada por cromatografia líquida de alta eficiência (CLAE). As análises foram feitas em duplicata e o tempo de equilíbrio considerado alcançado quando a concentração da solução analisada permaneceu constante.

\section{Ensaios de adsorção e dessorção}

Para os ensaios de adsorção, prepararam-se, inicialmente, soluções-padrão dos herbicidas em metanol (grau HPLC), na concentração de $1.000 \mathrm{mg} \mathrm{L}^{-1}$. A partir delas, foram feitas novas soluções em $\mathrm{CaCl}_{2} \quad 0,01 \mathrm{~mol} \mathrm{~L}^{-1}$ contendo $0,5,10,25,50$ e $100 \mu \mathrm{mL}^{-1}$ e 0 , $0,25,0,5,1,0,2,0$ e $4,0 \mu g \mathrm{~mL}^{-1}$ de ametryn e trifloxysulfuron-sodium, res pectivamente, sendo adicionados $10,0 \mathrm{~mL}$ dessas soluções a tubos de polipropileno com 2,0 g de cada solo. $\mathrm{O} \mathrm{pH}$ das suspensões foi corrigido, no início dos ensaios de adsorção, para 5,4 $\pm 0,1$,

Tabela 1 - Principais características físicas e químicas dos solos utilizados no estudo de adsorção e dessorção de ametryn e trifloxysulfuron-sodium

\begin{tabular}{|c|c|c|c|c|c|c|c|}
\hline \multirow{2}{*}{$\begin{array}{c}\text { Característica } \\
\text { avaliada }\end{array}$} & & \multicolumn{6}{|c|}{ Solo $^{1 /}$} \\
\hline & & SL & JP & CE & PN & TM & SSP \\
\hline $\mathrm{pH}^{2 /}$ & \multirow{4}{*}{$\left(\mathrm{cmol}_{\mathrm{c}} \mathrm{dm}^{-3}\right)$} & 5,40 & 5,10 & 6,80 & 6,20 & 5,40 & 5,40 \\
\hline $\mathrm{H}^{+}+\mathrm{Al}^{+3}$ & & 11,48 & 4,29 & 1,78 & 1,32 & 2,97 & 4,32 \\
\hline $\mathrm{SB}^{3 /}$ & & 4,41 & 0,58 & 10,00 & 4,86 & 0,87 & 1,53 \\
\hline $\mathrm{CTC}^{4 /}$ & & 15,89 & 4,87 & 11,78 & 6,18 & 3,84 & 5,85 \\
\hline $\mathrm{V}^{\frac{5}{5}}$ & \multirow{2}{*}{$(\%)$} & 27,7 & 11,9 & 84,9 & 78,6 & 22,7 & 26,1 \\
\hline $\mathrm{MO}^{6 /}$ & & 4,0 & 1,5 & 2,6 & 1,6 & 1,0 & 2,2 \\
\hline \multirow{3}{*}{ Fração Mineral (\%) } & Areia & 14 & 57 & 39 & 58 & 73 & 28 \\
\hline & Silte & 12 & 7 & 23 & 12 & 5 & 19 \\
\hline & Argila & 74 & 36 & 38 & 30 & 22 & 53 \\
\hline Text. $^{\text {I/ }}$ & \multirow{2}{*}{$(\%)$} & MA & AA & FA & FAA & FAA & $\mathrm{A}$ \\
\hline $\mathrm{ADA}^{8 !}$ & & 52 & 30 & 26 & 20 & 12 & 29 \\
\hline $\mathrm{EU}^{9 /}$ & $\left(\mathrm{kg} \mathrm{kg}^{-1}\right)$ & 0,343 & 0,137 & 0,219 & 0,186 & 0,094 & 0,209 \\
\hline Classif..$^{10 /}$ & & LVdf & LVAd & $\mathrm{LVe}$ & PVAe & RQ & $\mathrm{LVd}$ \\
\hline
\end{tabular}

${ }^{1}$ SL - Sete Lagoas; JP - João Pinheiro; CE - Capinópolis; PN - Ponte Nova; TM - Três Marias; SSP - São Sebastião do Paraíso. ${ }^{21} \mathrm{pH}$ em água: relação 1:2,5. ${ }^{3 /} \mathrm{SB}$ - soma de bases (Ca, Mg e Al: extrator KCL $1 \mathrm{~mol} \mathrm{~L}^{-1}$, K: extrator Mehlich I, H + Al: extrator Acetato de Cálcio 0,5 mol L $\left.{ }^{-1}, 7,0\right) .{ }^{4}$ CTC capacidade de troca de cátions - estimada ao $\mathrm{pH} 7,0 .{ }^{5 /} \mathrm{V}$ - saturação de bases. ${ }^{\mathbb{6}} \mathrm{MO}$ - matéria orgânica. ${ }^{\mathbb{Z}}$ Textura: FAA - Franco-Argilo-Arenosa;

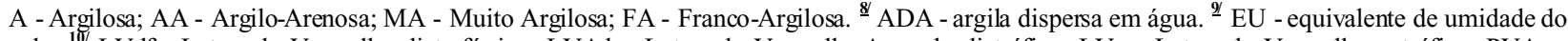
solo. $\underline{\underline{10} \mathbf{l}}$ LVdf - Latossolo Vermelho distroférrico; LVAd - Latossolo Vermelho-Amarelo distrófico; LVe - Latossolo Vermelho eutrófico; PVAe Argissolo Vermelho-Amarelo eutrófico; RQ - Neossolo Quartzarênico; LVd - Latossolo Vermelho distrófico. 
simulando-se o pH minimo para condições de cultivo agrícola. Após agitação dos tubos, por tempo previamente determinado e temperatura variando de $24 \pm 2,0{ }^{\circ} \mathrm{C}$, estes foram colocados em centrífuga a $1.600 \mathrm{xg}$ por sete minutos, com separação e filtração da fração sobrenadante em filtro Millipore com membrana PTFE 0,45 $\mu \mathrm{m}$, para posterior análise por CLAE. Os coeficientes de dessorção foram determinados para as maiores concentrações avaliadas de cada composto (100 $\mu \mathrm{g} \mathrm{mL}^{-1}$ de ametryn e 4,0 $\mu \mathrm{g} \mathrm{mL}^{-1}$ de trifloxysulfuron-sodium). Assim, após a retirada do volume sobrenadante do tubo, a mesma quantidade foi readicionada da solução de $\mathrm{CaCl}_{2}$ 0,01 $\mathrm{mol} \mathrm{L}^{-1}$ isenta do herbicida. Novamente, os tubos foram submetidos à agitação por tempo determinado, com posterior coleta e filtração da fração sobrenadante. O procedimento de dessorção foi repetido por três vezes, sem a alteração do $\mathrm{pH}$ da solução. Todos os ensaios (adsorção e dessorção) foram conduzidos em duplicata.

A quantificação dos herbicidas foi realizada utilizando-se cromatógrafo líquido Shimadzu SPD 2A, equipado com detector UV a $245 \mathrm{~nm}$ e coluna Varian de fase reversa C-18 $(250 \times 4$ $\mathrm{mm})$ e $5 \mu \mathrm{m}$ de espessura de poro. O volume de injeção foi de $20 \mu \mathrm{L}$ e a fase móvel composta por acetonitrila, água e ácido fosfórico, na respectiva proporção de 48:52:1 (v:v:v), com fluxo de $1 \mathrm{~mL} \mathrm{~min}^{-1}$. Utilizou-se para quantificação dos princípios ativos o método do padrão externo em solução de $\mathrm{CaCl}_{2} 0,01 \mathrm{~mol} \mathrm{~L}^{-1}$. A quantificação em $\mu \mathrm{g} \mathrm{mL} \mathrm{m}^{-1}$ foi realizada por meio da comparação das áreas obtidas nos cromatogramas para cada ensaio com as áreas dos cromatogramas das curvas-padrão (grau técnico) de cada herbicida. Após a quantificação do herbicida que ficou na solução em equilíbrio com o substrato (Ce) em $\mu \mathrm{g} \mathrm{mL}^{-1}$, utilizou-se a equação $\mathrm{x} / \mathrm{m}=\mathrm{v} / \mathrm{m}(\mathrm{Cp}-\mathrm{Ce})$ para o cálculo da quantidade do herbicida adsorvido ao solo $(\mathrm{x} / \mathrm{m})$, em $\mathrm{mL} \mathrm{g}^{-1}$, em que $\mathrm{v}=$ volume da solução de $\mathrm{CaCl}_{2}, 0,01 \mathrm{~mol} \mathrm{~L}^{-1}$ adicionado com o herbicida $(\mathrm{mL}) ; \mathrm{m}=$ massa de substrato (g solo); e $\mathrm{Cp}=$ concentração do herbicida na solução-padrão adicionada ( $\mu \mathrm{g} \mathrm{mL}^{-1}$ ).

Após obtenção dos valores de $\mathrm{x} / \mathrm{m}$ e de posse do valor de Ce para cada combinação solo, herbicida e concentração do herbicida, utilizou-se a equação de Freundlich para obtenção dos coeficientes de adsorção. Conhecidas como isotermas de Freundlich, as curvas são muito usadas para ensaios de adsorção de herbicidas em solos e servem de interpretação do processo adsortivo, estabelecendo a correlação entre a quantidade de herbicida adsorvido $(\mathrm{x} / \mathrm{m})$ e a quantidade na solução em equilíbrio (Ce). A partir da sua equação, $x / m$ $=\mathrm{Kf} \mathrm{Ce}{ }^{n}$, ajustaram-se os dados obtidos, sendo $\mathrm{Kf}$ e $n$ as constantes empíricas que representam a capacidade e intensidade de adsorção, respectivamente. Calculou-se, também, o indice $\mathrm{H}$ de "histerese", pela equação $\mathrm{H}=n_{\mathrm{a}} /$ $n_{\mathrm{d}}$, que representa a capacidade do composto em permanecer adsorvido, sendo $n_{\mathrm{a}}$ e $n_{\mathrm{d}}$ as curvaturas obtidas nas curvas de adsorção e dessorção, respectivamente.

Para obtenção dos coeficientes de dessorção e avaliação dos resultados de adsorção, os parâmetros de Freundlich $\mathrm{x} / \mathrm{m}$ e Ce foram submetidos à função logarítmica, sendo estimadas as equações lineares com os parâmetros $\log \mathrm{kf} \mathrm{e} n$.

A partir das equações de regressões lineares de $\log (\mathrm{x} / \mathrm{m})$ em função de $\log (\mathrm{Ce})$, aplicou-se o teste $\mathrm{F}$ a $5 \%$ de probabilidade, com o objetivo de testar a igualdade dos modelos de cada solo, em cada herbicida, separadamente. Análise de correlação de Pearson também foi realizada entre as propriedades dos solos estudados, e os coeficientes obtidos foram $\mathrm{Kf}$ e $n$, a $5 \%$ de probabilidade pelo teste $\mathrm{t}$.

\section{RESULTADOS E DISCUSSÃO}

A partir das análises dos solos estudados (Tabela 1), verificaram-se diferenças entre os teores de matéria orgânica $(1,0$ a 4,0) e fração mineral (franco-argilo-arenosa a muito argilosa), caracterizando solos possivelmente distintos em relação à capacidade de adsorção. $\mathrm{Na}$ avaliação da fração argila, observou-se o predominio de caulinita e gibbsita sobre os demais minerais, para a maioria dos solos, apresentando pouca distinção entre estes (Figura 1).

Nos ensaios de determinação dos tempos de equilíbrio realizados para cada combinação solo e herbicidas, observou-se preliminarmente que, a partir de 12 horas de agitação dos solos com ametryn (Figura 2), a concentração da solução em contato com o solo não se alterou. 
Já no ensaio com o herbicida trifloxysulfuronsodium (Figura 3), verificou-se maior tendência de equilíbrio a partir de 48 horas, sendo
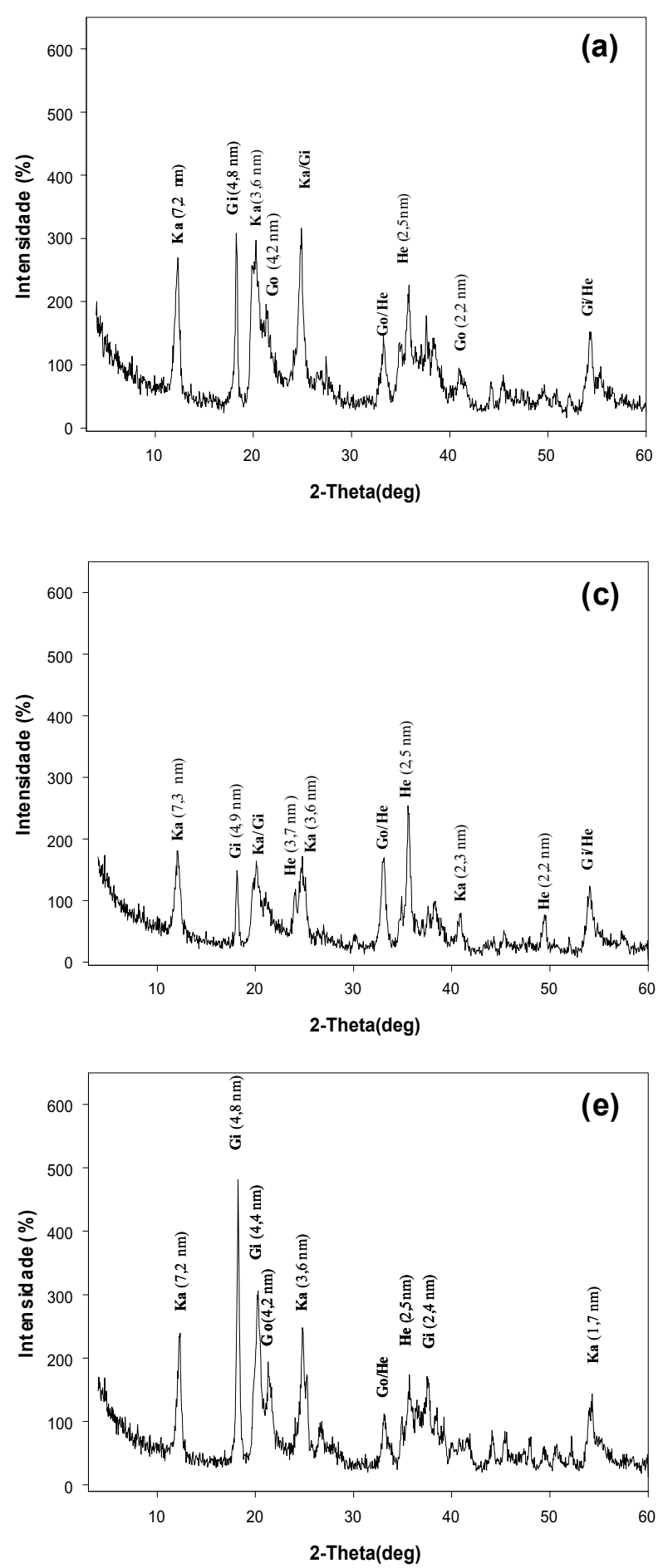

padronizados esses intervalos de tempo nos testes de adsorção e dessorção executados posteriormente.
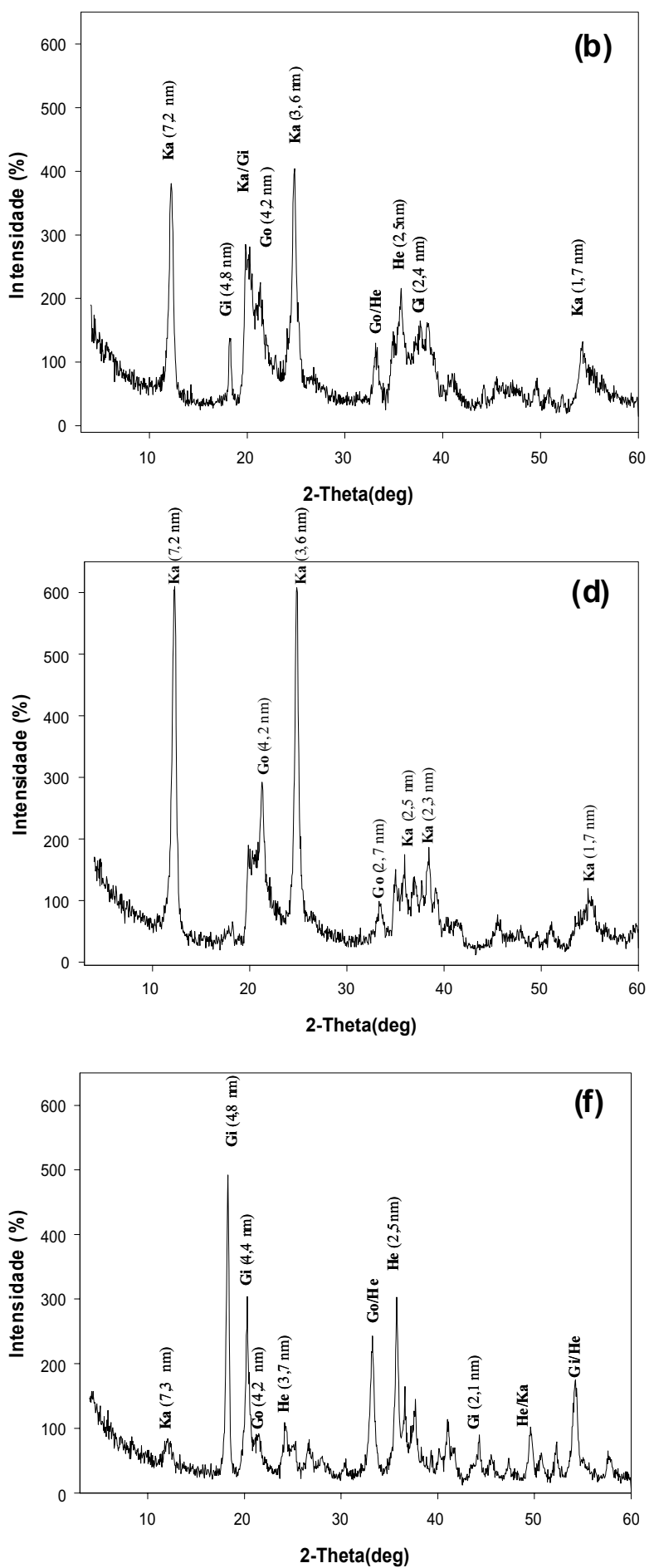

Figura 1 - Difratogramas de raio X [CuKa], da fração argila dos solos utilizados nos ensaios de adsorção e dessorção dos herbicidas ametryn e trifloxysulfuron-sodium. (a) LVdf (SL), (b) LVAd (JP), (c) LVe (CE), (d) PVAe (PN), (e) RQ (TM) e (f) LVd (SSP). Ka: caulinita; Go: goethita; Gi: gibbsita; He: hematita. 


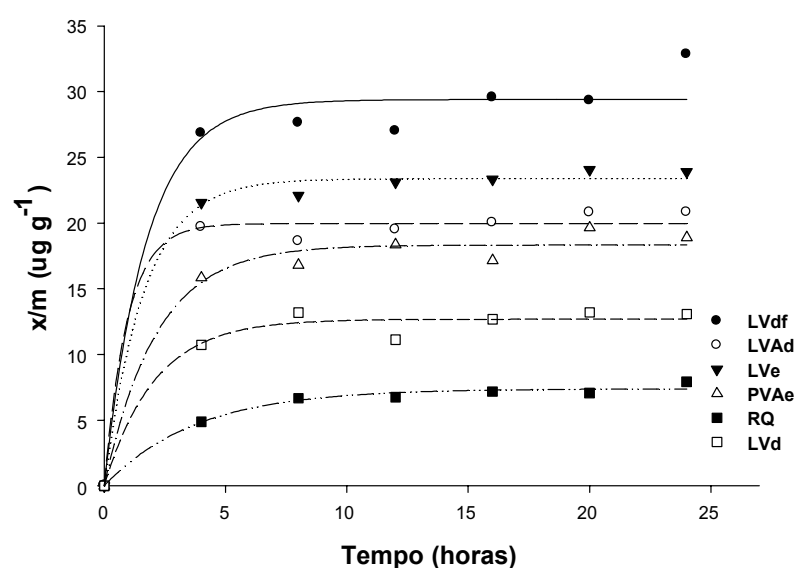

Figura 2 - Estimativas das curvas de cinética de adsorção para ametryn em diferentes solos: LVdf (SL) $\hat{Y}=29,3881$ (1-exp(-0,5767T); LVAd (JP) $\hat{Y}=19,958(1-\exp (-1,046 \mathrm{~T})$; LVe (CE) $\hat{Y}=23,3757(1-\exp (-0,6146 \mathrm{~T})$; PVAe (PN) $\hat{Y}=$ 18,3247(1-exp(-0,4658T); RQ (TM) $\hat{Y}=7,3894(1-\exp$ $(-0,2661 \mathrm{~T}) ;$ e LVd (SSP) $\hat{Y}=12,6838(1-\exp (-0,4829 \mathrm{~T})$, em função do tempo (T) em horas.

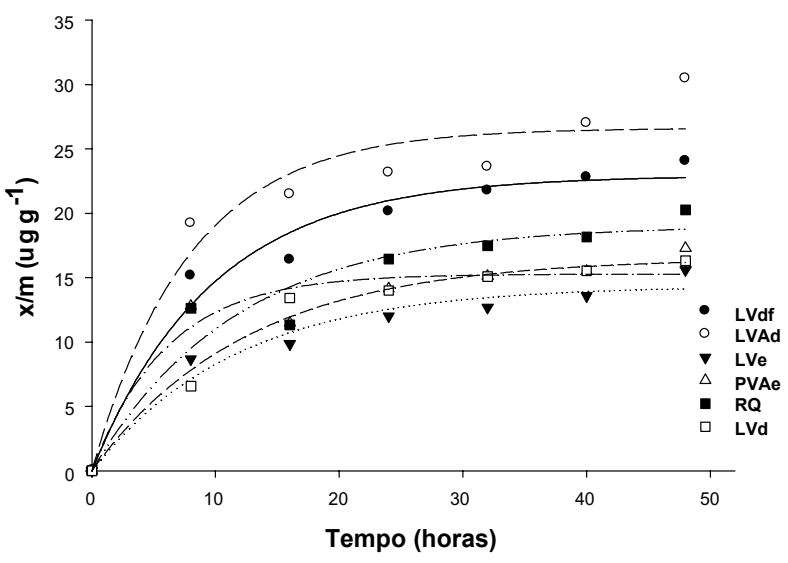

Figura 3 - Estimativas das curvas de cinética de adsorção para trifloxysulfuron-sodium em diferentes solos: LVdf (SL) $\hat{\mathrm{Y}}=22,9367(1-\exp (-0,1027 \mathrm{~T}) ; \operatorname{LVAd}(\mathrm{JP}) \quad \hat{\mathrm{Y}}=26,6125$ (1-exp(-0,1262T); LVe (CE) $\hat{Y}=14,3875(1-\exp (-0,0859 \mathrm{~T})$; PVAe (PN) $\hat{Y}=15,285(1-\exp (-0,1638 \mathrm{~T}) ; \mathrm{RQ}(\mathrm{TM})$ $\hat{Y}=19,0575(1-\exp (-0,0864 \mathrm{~T})$; e LVd (SSP) $\hat{Y}=16,5406$ (1-exp(-0,0800T), em função do tempo (T) em horas.

Para determinação da adsorção com ametryn, constatou-se maior coeficiente Kf no solo LVdf-(SL) (Tabela 1), sendo de $6,75 \mathrm{~mL} \mathrm{~g}^{1}$ (Figura 4). Este solo, juntamente com PVAe(PN), LVd-(SSP) e LVe-(CE), apresentaram os maiores Kf, os quais estão entre os solos com maior teor de MO. Resultados semelhantes foram relatados por diversos autores para atrazine, pertencente à mesma classe do ametryn (Procópio et al., 2001; Abate et al., 2004). Embora os herbicidas apresentem características moleculares distintas, a matéria orgânica (MO) do solo é responsável pelo aumento adsortivo de diversos compostos e desempenha importante papel, segundo Viera et al. (1999), na adsorção de contaminantes ambientais como herbicidas e metais pesados e, como conseqüência, na diminuição da lixiviação destes no perfil dos solos (Oliveira Jr. et al., 2001; Prata et al., 2001; Regitano et al., 2001; Dyson et al., 2002). Segundo a teoria de Brusseau \& Rao (1989), a MO é o principal material adsorvente dos solos, possuindo sítios tridimensionais que atuam na retenção dos compostos iônicos e não-iônicos.

Os demais solos apresentaram Kf inferiores em relação ao LVdf-(SL) para ametryn, constatando-se a menor capacidade adsortiva para o solo RQ-(TM) (Figura 4). Além do menor teor de MO, esse solo apresenta elevado percentual de areia na sua fração mineral (Tabela 1), a qual possui baixa capacidade de adsorção. Clausen et al. (2001) observaram menos de $1 \%$ de adsorção de diferentes herbicidas em

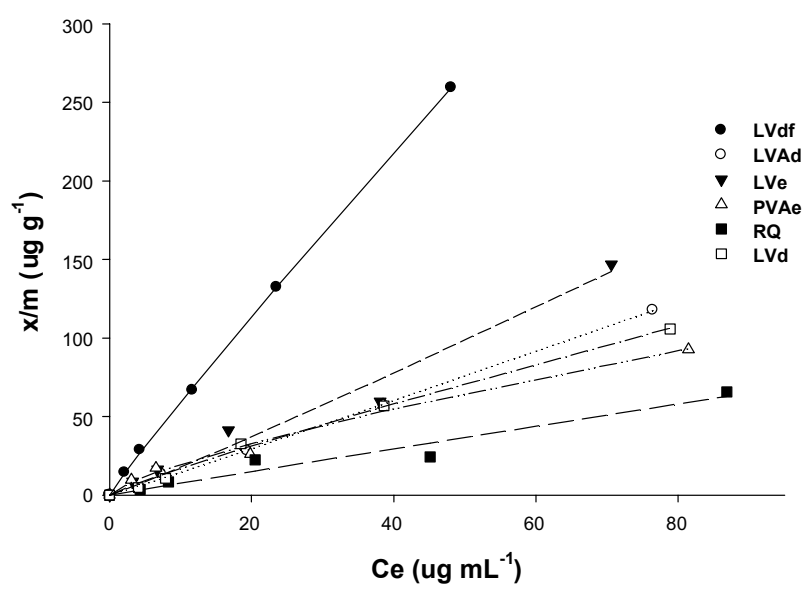

Figura 4 - Estimativas das isotermas de adsorção de Freundlich para ametryn nos solos LVdf(SL) $\hat{\mathrm{Y}}=6,7533 \mathrm{Ce}^{0,9420}$; LVAd (JP) $\hat{Y}=1,3503 \mathrm{Ce}^{1,0296} ; \mathrm{LVe}(\mathrm{CE}) \hat{\mathrm{Y}}=1,5118 \mathrm{Ce}^{1,0674} ; \mathrm{PVAe}$ (PN) $\hat{\mathrm{Y}}=3,5533 \mathrm{Ce}^{0,7425}$; RQ (TM) $\hat{\mathrm{Y}}=0,7951 \mathrm{Ce}^{0,9790}$; e $\operatorname{LVd}(\mathrm{SSP}) \hat{\mathrm{Y}}=2,1793 \mathrm{Ce}^{0,890}$, em função da solução em equilíbrio $(\mathrm{Ce})$. 
quartzo, o qual é constituinte da fração areia dos solos. A ordem de adsorção verificada para ametryn, conforme os coeficientes Kf e $n$ para uma mesma concentração considerada, foi: LVdf-(SL)> PVAe-(PN)> LVd-(SSP)> LVe- $(\mathrm{CE})>$ LVAd-(JP)> RQ-(TM). A consideração do coeficiente $n$ da isoterma de Freundlich é importante para prever a capacidade de adsorção dos solos, assim como observado por Leone et al. (2001) em ensaios de adsorção de três imidazolinonas, pois, mesmo que se verifique elevado coeficiente de adsorção Kf para a mesma concentração de herbicida testada, o valor exponencial de $n$ pode indicar pronunciada redução na quantidade adsorvida, quando for muito inferior a 1 .

Embora os solos não tenham seguido a ordem crescente de adsorção, proporcional aos teores de $\mathrm{MO}$, sabe-se que a composição do material orgânico é fundamental na capacidade adsortiva dos compostos. Chefetz et al. (2004) observaram maior adsorção de ametryn em sedimento com 1,25 dag $\mathrm{kg}^{-1}$ de carbono orgânico, em relação a outro com $1,63 \mathrm{dag} \mathrm{kg}^{-1}$. Os autores atribuíram esse comportamento ao fato de o sedimento de maior adsorção apresentar maior conteúdo de compostos aromáticos na fração orgânica, seguido de menor número de polissacarídeos, o que favorece a sua capacidade adsortiva.

A maior capacidade de adsorção de herbicidas em solos com elevados teores de material orgânico é relatada por muitos autores (Procópio et al., 2001; Rocha et al., 2003), os quais constataram que a fração húmica apresenta maior correlação na adsorção dos herbicidas, em relação ao teor de matéria orgânica total do solo. Dentre os componentes da fração húmica, também foram demonstradas especificidades na adsorção de herbicidas iônicos e não-iônicos com os teores de humina da matéria orgânica do solo (Procópio et al., 2001). Entretanto, existe grande complexidade e variabilidade da matéria orgânica presente em diferentes solos. Essas diferenças podem interferir não só na retenção dos herbicidas, mas também na sua transformação e transporte.

Sabe-se também que, além do carbono orgânico, o pKa do herbicida, o tipo e a quantidade de óxidos presentes são extremamente importantes na adsorção em solos tropicais altamente intemperizados. Conforme
Schwarzenbach et al. (1993), herbicidas iônicos podem interagir com sítios de superficie por meio de interações eletrostáticas, troca de íons ou por complexação, sendo essas interações significantes na adsorção por superficies minerais. Isso pode ser evidenciado pelo comportamento de trifloxysulfuronsodium (Figura 5). Esse herbicida, com pKa de 4,76, possui caráter ácido fraco, apresentando-se $50 \%$ na forma dissociada e $50 \%$ não dissociado quando o $\mathrm{pH}$ do meio é igual ao seu pKa. Portanto, no $\mathrm{pH}$ estabelecido nos ensaios adsortivos, de 5,4 $\pm 0,1$, mais de $50 \%$ da sua composição estava na forma aniônica, o que o torna extremamente dependente dos minerais presentes nos solos com cargas variáveis em função do $\mathrm{pH}$ do meio (Leone et al., 2001). Sabe-se que, para os herbicidas de caráter ácido, quanto menor o $\mathrm{pH}$ do solo em relação ao $\mathrm{pK}_{\mathrm{a}}$ do herbicida, maior será a tendência do herbicida em permanecer na forma molecular (neutra) e de se adsorver nas partículas coloidais do solo. A presença de óxidos e hidróxidos de ferro e alumínio nos solos estudados, além da caulinita (Figura 1), possibilita a formação de sítios adsortivos para formas aniônicas de compostos orgânicos presentes. A maioria desses minerais, com exceção da caulinita, apresenta ponto de carga zero (PCZ) entre 6 e 8,5 (Greenland \& Mott, 1978), o qual corresponde ao valor de $\mathrm{pH}$ em

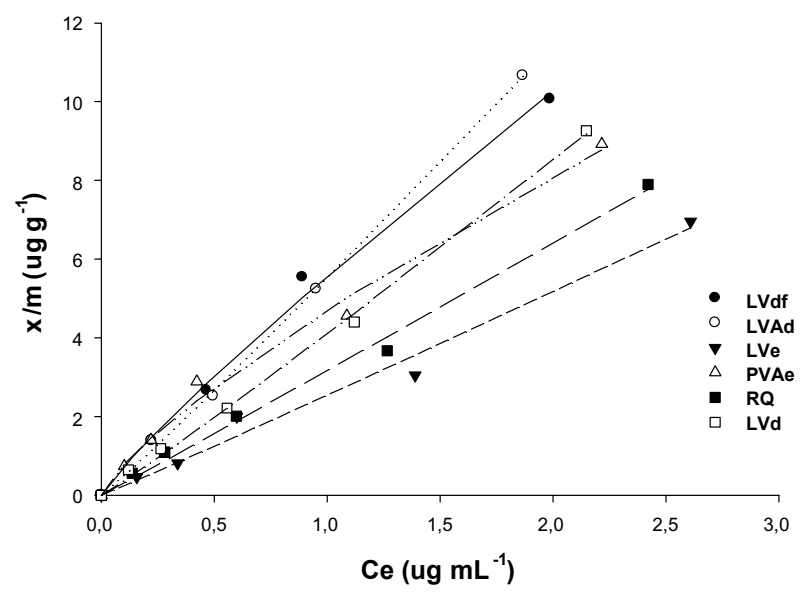

Figura 5 - Estimativas das isotermas de adsorção de Freundlich para trifloxysulfuron-sodium nos solos LVdf (SL) $\hat{\mathrm{Y}}=5,5677 \mathrm{Ce}^{0,8841} ; \operatorname{LVAd}(\mathrm{JP}) \hat{\mathrm{Y}}=5,5282 \mathrm{Ce}^{1,049} ; \mathrm{LVe}(\mathrm{CE})$ $\hat{\mathrm{Y}}=2,538 \mathrm{Ce}^{1,0266} ; \mathrm{PVAe}(\mathrm{PN}) \hat{\mathrm{Y}}=4,7094 \mathrm{Ce}^{0,7821} ; \mathrm{RQ}(\mathrm{TM})$ $\hat{\mathrm{Y}}=3,1664 \mathrm{Ce}^{1,0158}$; e LVd (SSP) $\hat{\mathrm{Y}}=4,1010 \mathrm{Ce}^{1,0548}$, em função da solução em equilíbrio (Ce). 
que a carga superficial do sistema é nula. Abaixo do seu PCZ, eles podem se tornar positivamente carregados com capacidade de adsorção de moléculas aniônicas, como o herbicida trifloxysulfuron-sodium.

No entanto, a quantidade de cargas geradas é distinta e variável para cada composição do solo, e as variações dos PCZ de cada mineral dependem da natureza acídica dos grupamentos $\mathrm{OH}$ da sua superfície. Observando-se os parâmetros Kf e $n$ obtidos para trifloxysulfuron-sodium, a ordem de adsorção para uma mesma concentração considerada foi: LVAd-(JP)> LVdf-(SL)> LVd-(SSP)> PVAe$(\mathrm{PN})>\mathrm{RQ}-(\mathrm{TM})>\mathrm{LVe}-(\mathrm{CE})$. Verifica-se que o comportamento desses solos para a adsorção de trifloxysulfuron-sodium é variável e não segue nenhuma ordem estabelecida para as características apresentadas na Tabela 1 , assim como é pouco significativa sua distinção na composição da fração mineral dos solos (Figura 1). Pos sivelmente existam contribuições tanto da fração mineral como da fração orgânica na adsorção desse herbicida, sendo a fração mineral predominante na definição da capacidade adsortiva desse composto, conforme constatações realizadas por Pusino et al. (2004). Os dados obtidos para os coeficientes adsortivos de trifloxysulfuron-sodium não são totalmente esclarecedores para a ordem de adsorção observada para esse herbicida, provavelmente pelo fato de as superficies dos complexos adsortivos resultarem de múltiplas associações de oxi-hidróxidos, caulinita e minerais amorfos. Entretanto, outros estudos demonstram que a adsorção de herbicidas aniônicos em minerais de solos intemperizados é significativa. Goetz et al. (1989) constataram maior capacidade adsortiva de chlorimuron aos solos com maiores conteúdos de hematita e gibbsita. A importância de óxidos na adsorção de alguns herbicidas de caráter ácido, como as imidazolinonas, também foi reportada por Regitano et al. (1997); além da interação de argilorgânicos, a espécie predominante de argilomineral é determinante no processo de adsorção.

Segundo a classificação de Giles et al. (1960), as isotermas de Freundlich (Figuras 4 e 5) apresentaram comportamento do tipo L e $\mathrm{S}$, com predominância do tipo L (alta afinidade ao material adsorvente e curvatura inicial convexa) para ametryn e do tipo S (baixa afinidade com curvatura inicial côncava) para trifloxysulfuron-sodium. São consideradas do tipo L quando o parâmetro $n$ da equação de Freundlich for $<1,0$ e do tipo S quando $n>1,0$. Embora se saiba que esse comportamento pode variar em função da faixa de concentração utilizada nos ensaios de adsorção, verifica-se maior número de curvas do tipo L para herbicidas com elevada tendência de adsorção à MO.

Observa-se, na Tabela 2, que todos os coeficientes de dessorção $\mathrm{Kf}_{\mathrm{d}}$ foram superiores aos de adsorção $\mathrm{Kf}_{\mathrm{a}}$, assim como o oposto foi observado para o parâmetro $n$, sendo os estimados na dessorção $\left(n_{\mathrm{d}}\right)$ inferiores aos de adsorção $\left(n_{\mathrm{a}}\right)$. Comportamento similar foi observado por Selim \& Zhu (2005), cujo fato caracteriza o fenômeno de histerese verificado na maioria de herbicidas em solos. Observa-se ainda que a forma linearizada das isotermas de Freundlich mostrou-se satisfatória para a maioria das combinações solo vs. herbicida. Sabe-se que quando a intensidade de adsorção, identificada pela curvatura $(n)$, aproxima-se de 1 , maior é a semelhança entre os coeficientes obtidos pelas isotermas de Freundlich e a sua forma linearizada (função logarítmica), podendo-se utilizá-la para descrição do comportamento sortivo dos compostos. Entretanto, a adsorção de ametryn nos solos LVe-(CE), PVAe-(PN) e RQ-(TM) e de trifloxysulfuron-sodium nos solos PVAe-(PN) e RQ-(TM) foi melhor descrita pelas isotermas não-lineares de Freundlich.

Juntamente com os coeficientes adsortivos estimados pelo modelo de Freundlich na forma logaritmica (Tabela 2), observam-se os indices $\mathrm{H}$ de histerese para ametryn e trifloxysulfuronsodium. Verifica-se que os maiores indices, representando menor capacidade dessortiva, não correspondem à ordem decrescente de adsorção dos herbicidas. Isso significa que os mecanismos atuantes nos processos adsortivos são distintos para os solos e que sua compreensão não depende somente dos coeficientes de adsorção, mas da forma como cada composto interage na superficie adsorvente, sendo importante também a consideração do índice de histerese. Além disso, sabe-se que os mecanismos podem variar conforme a concentração inicial do herbicida (Clausen et al., 2001) e o seu percentual adsorvido (Chefetz et al., 2004), sendo fundamentais estudos que esclareçam 
Tabela 2 - Estimativas dos coeficientes de adsorção $\left(\mathrm{Kf}_{\mathrm{a}}\right.$ e $\left.\mathrm{n}_{\mathrm{a}}\right)$, dessorção $\left(\mathrm{Kf}_{\mathrm{d}}\right.$ e $\left.\mathrm{n}_{\mathrm{d}}\right)$ e índice de histerese - $\mathrm{H}$, dos herbicidas ametryn e trifloxysulfuron-sodium, estimados individualmente para cada solo

\begin{tabular}{|c|c|c|c|c|c|c|c|}
\hline \multirow{2}{*}{ Herbicida/Solos ${ }^{1 /}$} & \multicolumn{3}{|c|}{ Adsorção } & \multicolumn{3}{|c|}{ Dessorção } & \multirow{2}{*}{$\mathrm{H}\left(n_{\mathrm{d}} / n_{\mathrm{d}}\right)$} \\
\hline & $\log \mathrm{Kf}_{\mathrm{a}}$ & $n_{\mathrm{a}}$ & $\mathrm{R}^{2}$ & $\log \mathrm{Kf}_{\mathrm{d}}$ & $n_{\mathrm{d}}$ & $\mathrm{R}^{2}$ & \\
\hline \multicolumn{8}{|c|}{ Ametryn } \\
\hline SL - LVdf & 0,855 & 0,923 & 0,99 & 1,745 & 0,379 & 0,95 & 2,435 \\
\hline JP - LVAd & 0,073 & 1,070 & 0,98 & 1,485 & 0,303 & 0,99 & 3,531 \\
\hline $\mathrm{CE}-\mathrm{LVe}$ & 0,481 & 0,883 & 0,98 & 1,467 & 0,372 & 0,99 & 2,374 \\
\hline PN - PVAe & 0,644 & 0,679 & 0,97 & 1,121 & 0,442 & 0,99 & 1,536 \\
\hline $\mathrm{TM}-\mathrm{RQ}$ & 0,041 & 0,899 & 0,95 & 1,417 & 0,194 & 0,95 & 4,634 \\
\hline SSP - LVd & 0,089 & 1,048 & 0,99 & 1,409 & 0,311 & 0,97 & 3,370 \\
\hline \multicolumn{8}{|c|}{ Trifloxysulfuron-sodium } \\
\hline SL - LVdf & 0,748 & 1,060 & 0,98 & 0,979 & 0,069 & 0,98 & 15,362 \\
\hline JP - LVAd & 0,745 & 1,036 & 0,99 & 1,017 & 0,035 & 0,99 & 29,600 \\
\hline $\mathrm{CE}-\mathrm{LVe}$ & 0,419 & 0,948 & 0,98 & 0,766 & 0,165 & 0,98 & 5,745 \\
\hline PN - PVAe & 0,676 & 0,790 & 0,99 & 0,904 & 0,133 & 0,99 & 5,940 \\
\hline TM - RQ & 0,516 & 0,897 & 0,99 & 0,889 & 0,017 & 0,97 & 52,764 \\
\hline SSP - LVd & 0,620 & 0,917 & 0,99 & 0,943 & 0,051 & 0,94 & 17,980 \\
\hline
\end{tabular}

${ }^{1 /}$ SL - Sete Lagoas (LVdf); JP - João Pinheiro (LVAd); CE - Capinópolis (LVe); PN - Ponte Nova (PVAe); TM - Três Marias (RQ); SSP - São Sebastião do Paraíso (LVd).

os mecanismos envolvidos. Morillo et al. (2004) evidenciaram comportamento similar entre os coeficientes de histerese e o teor de MO dos solos avaliados, sugerindo também que a MO não é o único fator que controla a dessorção dos compostos em solos.

Verifica-se, em média, que o índice de histerese para trifloxysulfuron-sodium foi superior ao observado para ametryn, indicando que, uma vez adsorvido, o trifloxysulfuronsodium dificilmente retorna à solução do solo. Já para ametryn, sua dessorção ocorre mais facilmente, representando maior risco no seu processo de lixiviação. Conforme Southwick et al. (1993), elevados indices de histerese indicam maior dificuldade de o herbicida adsorvido retornar à solução do solo, possibilitando sua maior permanência no ambiente. Em acordo com os dados obtidos para ametryn, Chefetz et al. (2004) também verificaram menor histerese para esse composto em relação à atrazine, potencializando a sua capacidade de lixiviação, mesmo após a sua adsorção no solo.

Para os elevados índices $\mathrm{H}$ de histerese observados em trifloxysulfuron-sodium, duas hipóteses podem ser descritas: os prováveis mecanismos de adsorção entre o herbicida e os minerais dos solos (caulinita e óxidos de $\mathrm{Fe}$ e Al) atuam de forma específica, com elevada força de ligação, impedindo que o processo reverso de dessorção ocorra; e o processo de agitação prolongado pode provocar aumento na capacidade de adsorção dos solos pela mudança na estrutura dos seus agregados, não tendo a mistura solo:solução alcançado o tempo real de equilíbrio, com continuação do processo de adsorção nos ensaios de dessorção posteriores.

As duas hipóteses já foram relatadas na literatura. Locke et al. (1992) observaram que o verdadeiro equilíbrio para alachlor só foi alcançado após 48 horas de agitação, sendo o mesmo fundamental na comparação dos coeficientes adsortivos. Por sua vez, Kung \& McBride (1989) concluíram que a adsorção de herbicidas aniônicos por óxidos de Fe é geralmente atribuída ao mecanismo por troca de ligantes, com forte ligação do adsorvente ao adsorvato, o que dificulta o processo de dessorção. Esse mecanismo permite a formação de complexos de esfera interna a partir da substituição de um grupo hidroxila, ligado ao $\mathrm{Fe}$, por um grupo funcional do composto orgânico. Parfitt et al. (1977) também relatam a formação de ligações fortes para minerais, 
conforme observado entre goethita e compostos orgânicos por mecanismo de troca de ligantes. Embora se verifiquem discordâncias quanto aos prováveis mecanismos de adsorção dos herbicidas ácidos fracos encontrados na literatura, acredita-se que ocorra realmente a formação de fortes ligações entre o herbicida trifloxysulfuron-sodium e os minerais encontrados nos solos. Esses mecanismos resultariam em baixa dessorção do herbicida, com elevado índice $\mathrm{H}$ de histerese, conforme constatado na Tabela 2. Ressalta-se ainda, nesta tabela, que os menores índices $\mathrm{H}$ para o trifloxysulfuron-sodium são verificados para os solos LVe-(CE) e PVAe-(PN). Por serem solos eutróficos, com elevada saturação de bases, a força iônica da solução do solo pode interferir na capacidade de adsorção e, principalmente, no processo dessortivo desses solos. Os íons presentes, principalmente $\mathrm{Ca}^{+2}$, podem formar complexos com as fórmulas aniônicas de herbicidas presentes na solução, enfraquecendo as forças de ligação desses compostos com os argilominerais e facilitando o processo de dessorção destes. Esse comportamento foi verificado por Clausen \& Fabricius (2001) em ensaios de adsorção de herbicidas ácidos, os quais constataram redução da adsorção em goethita e lepidocrocita com o aumento da concentração da solução de $\mathrm{CaCl}_{2}$ utilizada.

Na comparação entre as curvas de adsorção linearizadas, observa-se similaridade dos parâmetros obtidos para ametryn nos solos LVAd-(JP) e LVd-(SSP), resultando em uma única equação, apresentada na Figura 6. Já para trifloxysulfuron-sodium, os solos LVdf-(SL) juntamente com LVAd-(JP), e RQ(TM) com LVd-(SSP), apresentaram comportamento similar, resultando em uma única equação em cada combinação (Figura 7). Entretanto, não foi possivel a junção entre as equações de dessorção dos solos para ambos os herbicidas, enfatizando a variação e o grau de interferência nos fenômenos dessortivos de herbicidas em solos (Figuras 8 e 9).

Os estudos de correlação apresentados na Tabela 3 confirmam as observações dos processos adsortivos de cada herbicida. Os valores de 0,80 e 0,81 ( $\mathrm{P}<0,05)$, obtidos para $\mathrm{Kf}$ do ametryn em relação aos teores de argila e MO do solo, respectivamente, enfatizam a maior capacidade de adsorção desse herbicida em solos com elevados teores de MO e de argila.

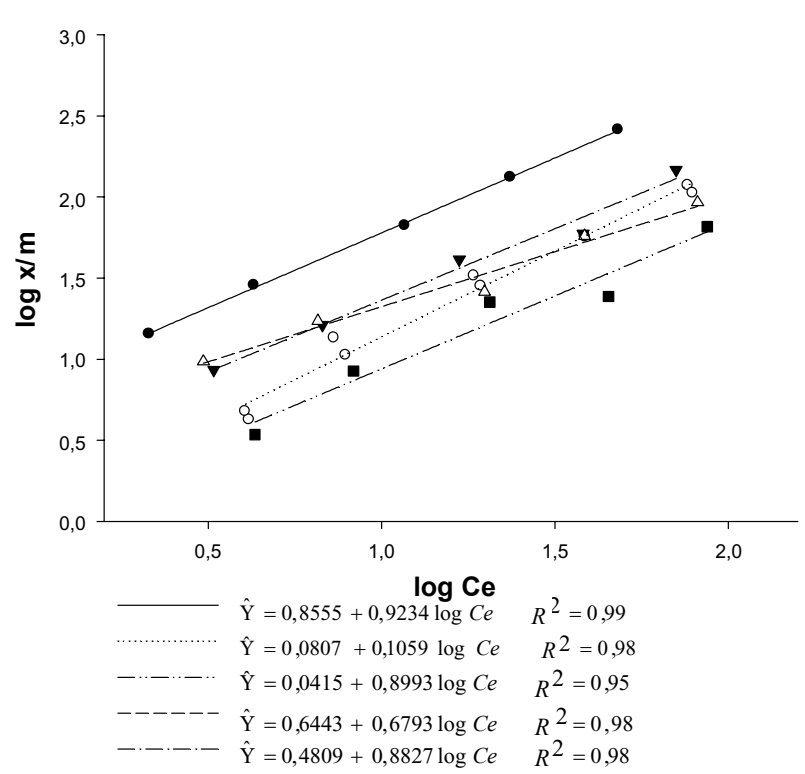

Figura 6 - Estimativas das curvas de adsorção para ametryn nos solos — - LVdf (SL); O - LVAd (JP) e LVd (SSP); $\boldsymbol{\nabla}$ - LVe (CE); $\triangle$ - PVAe (PN); e $\boldsymbol{~ - ~ R Q ~ ( T M ) , ~ e m ~ f u n c ̧ a ̃ o ~}$ do logaritmo da concentração da solução em equilíbrio $(\log \mathrm{Ce})$. As linhas representam o modelo linearizado da equação de Freundlich.

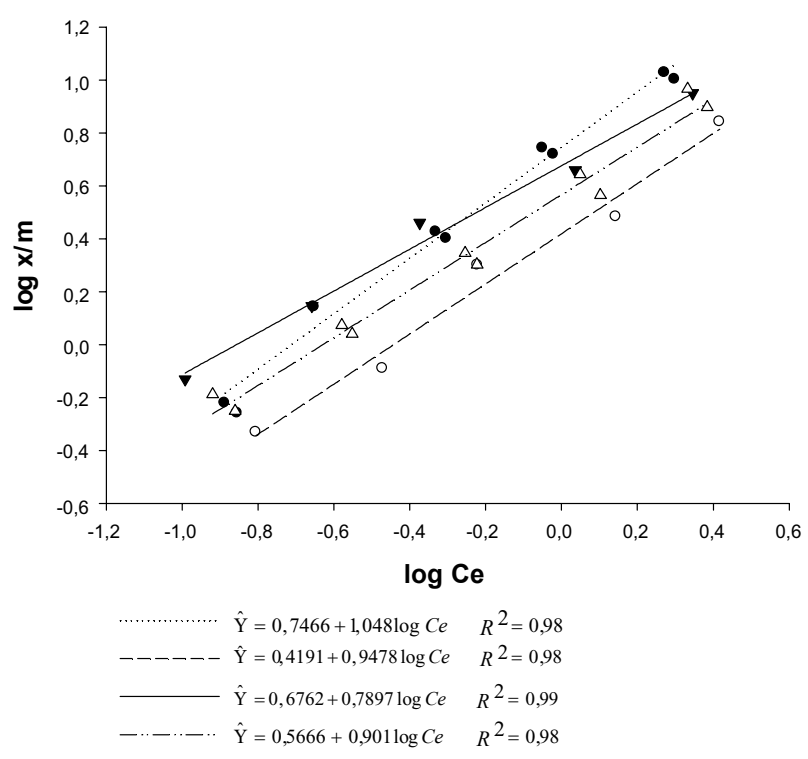

Figura 7 - Estimativas das curvas de adsorção para trifloxysulfuron-sodium nos solos: $\bullet$ - LVdf (SL) e LVAd (JP); O- LVe (CE); $\boldsymbol{\nabla}$-PVAe (PN); $\triangle$ - RQ (TM) e LVd (SSP), em função do logaritmo da concentração da solução em equilíbrio $(\log \mathrm{Ce})$. As linhas representam o modelo linearizado da equação de Freundlich. 


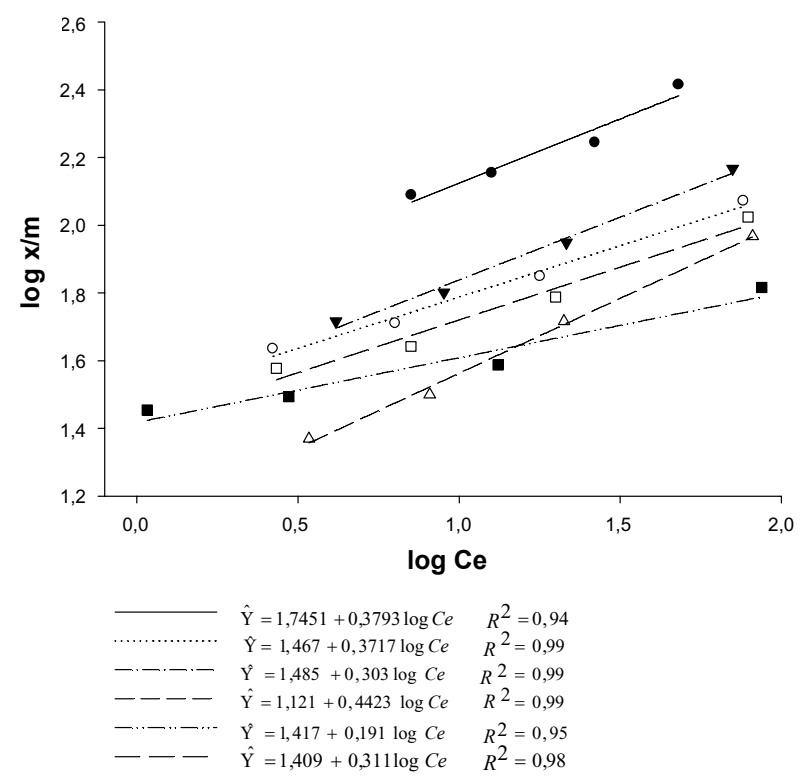

Figura 8 - Estimativas das curvas de dessorção para ametryn nos solos •- LVdf (SL); O- LVAd (JP); $\boldsymbol{\nabla}$ - LVe (CE); $\triangle$ - PVAe (PN); - - RQ (TM); e $\square$ - LVd (SSP), em função do logaritmo da concentração da solução em equilíbrio (log Ce). As linhas representam o modelo linearizado da equação de Freundlich.

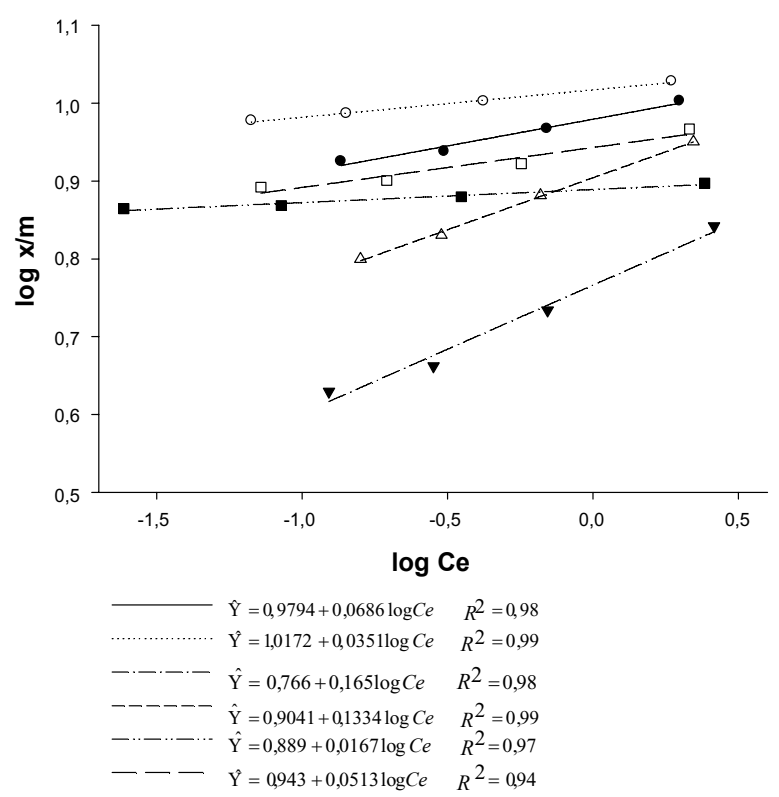

Figura 9 - Estimativas das curvas de dessorção para trifloxysulfuron-sodium nos solos: •- LVdf(SL); O- LVAd (JP); $\boldsymbol{\nabla}$ - LVe (CE); $\triangle$ - PVAe (PN); - RQ (TM); e $\square$ - LVd (SSP), em função do logaritmo da concentração da solução em equilíbrio $(\log \mathrm{Ce})$. As linhas representam o modelo linearizado da equação de Freundlich.

Tabela 3 - Estimativas das correlações de Pearson entre os coeficientes de adsorção e as principais características físicas e químicas dos solos

\begin{tabular}{|c|c|c|c|c|c|c|c|}
\hline \multirow{2}{*}{ Herbicida } & \multirow{2}{*}{ Coeficiente } & $\mathrm{CTC}^{1 /}$ & $\mathrm{MO}^{2 /}$ & $\mathrm{V}^{3 /}$ & $\mathrm{ARG}^{4 /}$ & $\mathrm{ADA}^{\frac{5 /}{1}}$ & $\mathrm{EU}^{6 /}$ \\
\hline & & \multicolumn{2}{|c|}{$\left(\mathrm{cmol}_{\mathrm{c}} \mathrm{dm}^{-3}\right)$} & \multicolumn{2}{|c|}{$(\%)$} & \multicolumn{2}{|c|}{$\left(\mathrm{kg} \mathrm{kg}^{-1}\right)$} \\
\hline \multirow{2}{*}{ Ametryn } & $\mathrm{Kf}$ & $0,75^{*}$ & $0,81^{*}$ & 0,02 & $0,80 *$ & $0,81^{*}$ & $0,88^{*}$ \\
\hline & $\mathrm{n}_{\mathrm{a}}$ & 0,19 & 0,10 & $-0,24$ & 0,00 & 0,11 & $-0,09$ \\
\hline \multirow{2}{*}{ Trifloxysulfuron-sodium } & $\mathrm{Kf}$ & 0,13 & 0,28 & $-0,46^{*}$ & $0,48^{*}$ & $0,61^{\text {* }}$ & 0,34 \\
\hline & $\mathrm{n}_{\mathrm{a}}$ & $-0,28$ & $-0,22$ & $-0,45$ & $-0,11$ & $-0,16$ & $-0,37$ \\
\hline
\end{tabular}

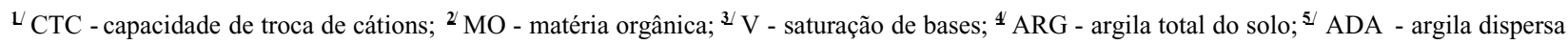
em água; ${ }^{\mathbb{G}} \mathrm{EU}$ - equivalente de umidade do solo; * Significativo pelo teste t $(\mathrm{P}<0,05)$.

Correlações positivas também foram observadas para CTC, equivalente de umidade (EU) e argila dispersa em água (ADA), as quais estão relacionadas à maior capacidade de retenção de água e elevada área superficial específica para os solos com teores de argila e matéria orgânica elevados. Esse comportamento verificado para ametryn é importante sob o ponto de vista prático, pois a sua eficiência pode ser reduzida em solos extremamente argilosos e com teores de MO elevados, assim como, em solos pobres em MO e com elevada dessorção, pode resultar na lixiviação desse herbicida até atingir águas subterrâneas e de superficie.

Ao analisar os valores obtidos para trifloxysulfuron-sodium, observam-se pequenas correlações positivas $(\mathrm{P}<0,05)$ com os teores de argila e de argila dispersa em água, as quais são decorrentes do seu processo de adsorção, sendo influenciado fortemente pelo tipo de mineral presente e pelo $\mathrm{pH}$ da solução do solo. Correlação negativa com a saturação de bases (V) evidencia novamente o processo 
competitivo entre os cátions em solução com o herbicida, em relação às cargas positivas de óxidos e hidróxidos de Fe e Al. A complexação das moléculas aniônicas de trifloxysulfuronsodium por íons $\mathrm{Ca}^{+2}$, principalmente, atuariam na redução da sua capacidade de adsorção. Em condições de campo, solos eutróficos ou com elevados niveis de adubação, a adsorção de trifloxysulfuron-sodium pode ser menor, possibilitando maior movimentação do herbicida no perfil do solo e, conseqüentemente, redução na sua atividade herbicida em condições de elevada precipitação.

Dessa forma, maior atenção deve ser dada ao monitoramento de ametryn em relação a trifloxysulfuron-sodium, sobretudo em países de clima tropical como o Brasil, no qual os solos agrícolas possuem baixos teores de matéria orgânica, que os predispõem à maior possibilidade de lixiviação desse herbicida. As doses comercialmente utilizadas também devem ser consideradas, pois, em média, para cada 100,0 g de ametryn utilizado, apenas 2,0 g de trifloxysulfuron-sodium são aplicados. Tendo em vista que a avaliação ambiental de herbicidas não deve ser limitada à análise de resultados de ensaios laboratoriais, sugere-se a execução de estudos em condições ambientais, para confirmação do comportamento desses compostos no solo.

\section{AGRADECIMENTOS}

À Companhia Syngenta S.A., pelo fornecimento do produto técnico. Aos professores Antônio A. Neves e Antônio J. Demuner, do Departamento de Química, e aos professores Jaime W. V. de Mello e Raphael B. A. Fernandes, do Departamento de Solos da UFV, pela colaboração.

\section{LITERATURA CITADA}

ABATE, G. et al. Influence of humic acid on adsorption and desorption of atrazine, hydroxyatrazine, deethylatrazine and deisopropylatrazine onto a clay-rich soil sample. J. Agric. Food Chem., v. 52, p. 6747-6754, 2004.

AHMAD, R. et al. Sorption of ametryn and imazethapyr in twenty five soils from Pakistan and Australia. J. Env. Sci. and Health B., v. 36 n. 2 p. 143-160, 2001.

BRUSSEAU, M. L.; RAO, P. S. C. The influence of sorbateorganic matter interactions on sorption nonequilibrium. Chemosphere, v. 18, n. 9/10, p. 1691-1706, 1989.
CHEFETZ, B. et al. Sorption-desorption behavior of triazine and phenylurea herbicides in Kishon river sediments. Water Res., v. 38, p. 4383-4394, 2004.

CLAUSEN, L.; FABRICIUS, I. Atrazine, isoproturon, mecoprop, 2,4-D and bentazone adsorption onto iron oxides. J. Environ. Qual., v. 30, p. 858-869, 2001.

DYSON, J. S. et al. Adsorption and degradation of the weak acid mesotrione in soil and environmental fate implications. J. Environ. Qual., v. 31, p. 613-618, 2002.

FONTES, M. P. et al. Eletroquímica das partículas coloidais e sua relação com a mineralogia de solos altamente intemperizados. Scientia Agrícola, v. 58, n. 3, p. 627-646, 2001.

GILES, C. H. et al. Studies in adsorption: part XI. A system of classification of solution adsorption isotherms, and its use in diagnosis of adsorption mechanism and in measurement of specific surface areas of solids. J. Chem. Soc., v. 111, p. 3973-3993, 1960.

GOETZ, A. J. et al. Sorption and mobility of chlorimuron in Alabama soils. Weed Sci., v. 37, p. 428-433, 1989.

GOODDY, D. C. et al. Pesticide pollution of the Triassic Sandstone aquifer of south Yorkshire. Quart. J. of Eng. Geol. and Hidrol., v. 38, p. 53-63, 2005.

GREELAND, D. J.; MOTT, C. J. B. Surfaces of soils particles. In: GREELAND, D. J.; HAYES, M. B. (Eds.). The chemistry of soil constituents. New York: John Wiley and Sons, 1978. p. 321-354.

HAGER, A.; NORDBY, D. Herbicide persistence and how to test for residues in soils. In: BISSONNETTE. S. Illinois agricultural pest management handbook. Illinois: University of Illinois, 2004. p. 323-326.

HINZ, C. Description of sorption data with isotherm equations. Geoderma v. 99, p. 225-243, 2001.

KUNG, K. H.; McBRIDE, M. B. Adsorption of parasubstituted benzoates on iron oxides. Soil Sci. Soc. Am. J., v. 53, p. 1673-1678, 1989.

LAABS, V. et al. Pesticides in surface water, sediment and rainfall of the northeastern Pantanal basin, Brasil. J. Environ. Qual., v. 31, p. 1636-1648, 2002.

LAVORENTI, A. Comportamento dos herbicidas no solo. In: ENCONTRO BRASILEIRO DE SUBSTÂNCIAS HÚMICAS, 3., 1999, Santa Maria. Anais... Santa Maria-RS, 1999. p. 21-34.

LEONE, P. et al. Role of ferrihydrite in adsorption of three imidazolinone herbicides. J. Agric. Food Chem., v. 49, p. 1315-1320, 2001. 
LI, H. et al. Sorption and desorption of pestides by clay minerals and humic acid-clay complexes. Soil Sci. Soc. Am., v. 67, p. 122-131, 2003.

LOCKE, M. A. et al. Sorption-desorption kinetics of alachlor in surface soil from two soybean tillage systems. J. Environ. Qual., v. 21, p. 558-566, 1992.

MORILLO, E. et al. Effect of soil type on adsorptiondesorption, mobility and activity of the herbicide norflurazon. J. Agric. Food Chem., v. 52, p. 884-890, 2004.

OLIVEIRA M. F. et al. Sorção e hidrólise do herbicida flazasulfuron. Planta Daninha, v. 23, n. 1, p. 101-113, 2005.

OLIVEIRA JR., R. S; KOSKINEN, W. C; FERREIRA, F. A. Sorption and leaching potential of herbicides in Brazilian soils. Weed Res., v. 41, p. 97-110-, 2001.

ORGANIZATION FOR ECONOMIC CO-OPERATION AND DEVELOPMENT - OECD. 1993. OECD guidelines for testing of chemicals, adsorption and desorption, 106. Paris: OECD, 1993.

PARFITT, R. L. et al. Adsorption on hydrous oxides. I. Oxalate and benzoate on goethite. J. Soil. Sci., v. 28, p. 29-39, 1977.

PRATA, F. et al. Degradação e sorção de ametrina em dois solos com aplicação de vinhaça. Pesq. Agropec. Bras., v. 36, n. 7, p. 975-981, 2001.

PROCÓPIO, S. O. et al. Sorção do herbicida atrazine em complexos organominerais. Planta Daninha, v. 19, n. 3, p. 391-400, 2001.

PUSINO, A. et al. Sorption of primisulfuron on soil, and inorganic and organic soil colloids. European J. of Soil Sci., v. 55, p. 175-182, 2004.

PUSINO, A. Influence of organic matter and its clay complexes on metolachlor adsorption on soil. Pesticide Sci., v. 31, p. 283-286, 1993.
RACKE, K. D. Pesticide fate in tropical soils. In: WORKSHOP ON PESTICIDES, USES AND ENVIRONMENTAL SAFETY IN LATIN AMERICA, 1996, São Paulo, SP. Book abstracts... São Paulo, Sociedade Brasileira de Química, 1996, p. 15.

REGITANO, J. B.; ALLEONI, L. R. F.; TORNISIELO, V. L. Atributos de solos tropicais e a sorção de imazaquin. Scientia Agrícola, v. 58, n. 4, p. 801-807, 2001.

REGITANO, J. B. et al. Retention of imazaquin in soil. Environ. Toxicol. Chem., v. 16, p. 397-404, 1997.

ROCHA, W. S. D.; ALLEONI, L. R. F.; REGITANO, J. B. Energia livre da sorção de imazaquin em solos ácricos. Rev. Bras. Ciência do Solo, v. 27, p. 239-246, 2003

RODRIGUES, B. N.; ALMEIDA, F. R. Guia de herbicidas 5.ed. Londrina: Edição dos Autores, 2005. p. 591.

SCHWARZENBACH, R. P. et al. Sorption: solid-aqueous solution exchange. In: SCHWARZENBACH, R. P. et al. (Eds.). Environmental organic chemistry. New York: John Wiley \& Sons, 1993, p. 255-341.

SELIM, H. M.; ZHU, H. Atrazine sorptio-desorption by sugarcane mulch residue. J. Environ. Qual., v. 34, p. 325-335, 2005.

SI, Y. et al. Influence of organic amendment on the adsorption and leaching of ethametsulfuron-methyl in acidic soils in China. Geoderma, v. 130, p. 66-76, 2006.

SOUTHWICK, M. L. et al. Hysteretic characteristics of atrazine adsorption-desorption by a sharkey soil. Weed Sci., v. 41, p. 627-633, 1993.

VIEIRA, E. V. et al. Estudo da adsorção/dessorção do ácido 2,4 diclorofenoxiacético (2,4-D) em solo na ausência e presença de matéria orgânica. Química Nova, v. 22, n. 3, p. 305-308, 1999. 